\title{
BMJ Global Health A planetary vision for one health
}

\author{
Peter MacGarr Rabinowitz, ${ }^{1}$ Marguerite Pappaioanou, ${ }^{2}$ Kevin Louis Bardosh, ${ }^{3}$ \\ Lisa Conti ${ }^{4}$
}

\begin{abstract}
To cite: Rabinowitz PMacG, Pappaioanou M, Bardosh KL, et al. A planetary vision for one health. BMJ Glob Health 2018;3:e001137. doi:10.1136/ bmjgh-2018-001137
\end{abstract}

Handling editor Seye Abimbola

Received 24 August 2018 Accepted 24 August 2018

Check for updates

(C) Author(s) (or their employer(s)) 2018. Re-use permitted under CC BY-NC. No commercial re-use. See rights and permissions. Published by BMJ.

${ }^{1}$ Department of Environmental and Occupational Health Science, Department of Global Health, Department of Family Medicine, Department of Medicine, Division of Allergy and Infectious Disease, Center for One Health Research, University of Washington, Seattle,

Washington, USA

${ }^{2}$ Department of Environmental and Occupational Health Sciences, Center for One Health Research, University of Washington, Seattle, Washington, United States ${ }^{3}$ Department of Anthropology, Department of Environmental and Global Health, Emerging Pathogens Institute, University of Florida, Gainesville, FL, United States

${ }^{4}$ Florida Department of Agriculture and Consumer Services, Tallahassee, Florida, USA

Correspondence to Professor Peter MacGarr Rabinowitz; peterr7@uw.edu

\section{PLANETARY HEALTH, ECOHEALTH AND ONE HEALTH}

In 2015, the Rockefeller Foundation-Lancet Commission published a report: Safeguarding Human Health in the Anthropocene Epoch. ${ }^{1}$ This report outlines the extent to which human activities have degraded the earth's ecosystems such that basic life support services have become threatened. Among the threats are greenhouse gases and resulting climate change, severe weather patterns, deforestation, desertification, ocean acidification, zoonotic disease outbreaks, biodiversity loss and particulate air pollution. The report concludes that these planetary phenomena pose a serious and urgent threat to human health, well-being and sustainability, and calls for immediate attention to critical multidisciplinary research, and evidence-based policy formulation and timely implementation.

The Lancet Commission report has spawned a number of Planetary Health efforts, focused on policy, education and research, with initial support provided by the Rockefeller Foundation and more recently the Wellcome Trust. ${ }^{2}$ Activities include formation of a Planetary Health Alliance of over 95 universities, non-governmental organisations, government entities, research institutes and other partners, a website portal, ${ }^{3}$ an annual Planetary Health conference, and a new journal dedicated to the topic. ${ }^{4}$

Interest in the Planetary Health approach has led to a re-examination of similar existing approaches such as One Health ${ }^{5}$ and EcoHealth. ${ }^{6}$ One Health, an interdisciplinary approach stressing connections between human, animal and environmental health, gained momentum as a response to the steadily increasing drumbeat of emerging zoonotic disease outbreaks in recent decades, including the West Nile virus, severe acute respiratory syndrome, Nipah and Hendra viruses, Ebola, avian influenza, H1N1 2009 pandemic influenza, ${ }^{5}$ and most recently Ebola in West Africa, zika and yellow fever. ${ }^{7}$ The threat to global health from antimicrobial resistance, now understood to stem from overuse of antibiotics in both humans and animals, with environmental accumulation of antibiotic residues and resistant organisms and genes, has led to further support for One Health solutions. ${ }^{8}$ A recent editorial in The $B M J$ highlighted the utility of a One Health approach. ${ }^{9}$

The One Health approach has now been endorsed by numerous international agencies, including the WHO, the United Nations Food and Agriculture Organisation and the World Organisation for Animal Health (OIE),${ }^{10}$ the US Centers for Disease Control and Prevention, the Emerging Pandemic Threat programme of the US Agency for International Development's (USAID/EPT) ${ }^{11}$ the European Union, ${ }^{12}$ the Wellcome Trust, ${ }^{2}$ the UK-based Fleming Fund, ${ }^{13}$ and the international Global Health Security Agenda. ${ }^{14}$ It has been a focus of discussion at diverse international meetings, including the Davos, Switzerland Economic Summit ${ }^{15}$ and Thailand's Prince Mahidol Award Conferences. ${ }^{16}$ The USAID/EPT programme has fostered the development of two One Health university networks-SEAOHUN in South-East Asia, and OHCEA in Eastern and Central Africathat are engaged in One Health workforce development in those regions. ${ }^{17}$

Despite such widespread and growing acceptance, the One Health approach has been criticised for an excessive focus on emerging zoonotic diseases, inadequate incorporation of environmental concepts and expertise, ${ }^{18}$ and insufficient incorporation of social science and behavioural aspects of health and governance. ${ }^{19}{ }^{20}$ Reviews of the burgeoning One Health literature have noted persistent scientific silos between human, animal and environmental sectors, ${ }^{21}$ the fact that many papers purporting to use a One Health approach actually consider only human and animal health (leaving out environmental health considerations), ${ }^{22}$ and that a need remains for additional proof-ofconcept demonstrations on the added value 
of simultaneously considering human, animal and environmental health issues and outcomes in a One Health framework. ${ }^{2324}$ To address such concerns, the recently published Checklist for One Health Epidemiological Reporting of Evidence ${ }^{25}$ registered on the EQUATOR (Quality and Transparency in Health Research) network, ${ }^{26}$ encourages greater rigour and transparency in the reporting of One Health epidemiological research.

How then does One Health relate to Planetary Health? In a recent review, Lerner and $\mathrm{Berg}^{27}$ define One Health as a concept that values interdisciplinarity, public health, animal health and ecosystem health. The related concept of EcoHealth is seen as focusing, primarily, on biodiversity as well as participatory knowledge-to-action approaches. Planetary Health, by contrast, in Lerner and Berg's ${ }^{27}$ opinion, has a more 'anthropocentric' perspective, viewing ecosystems (including animals as part of the biotic environment) largely in terms of their contribution to human health, well-being and sustainability.

\section{ONE HEALTH AS A SYSTEMS APPROACH INCORPORATING PLANETARY AND ECOHEALTH CONCEPTS}

While the importance of emerging zoonotic diseases should be obvious to the readers of BMJ Global Health, we argue for further development of the One Health framework to better incorporate Planetary and EcoHealth concepts and the sense of urgency regarding environmental support systems. This expanded One Health framework builds on earlier systems approaches to human health, such as the biopsychosocial model of health

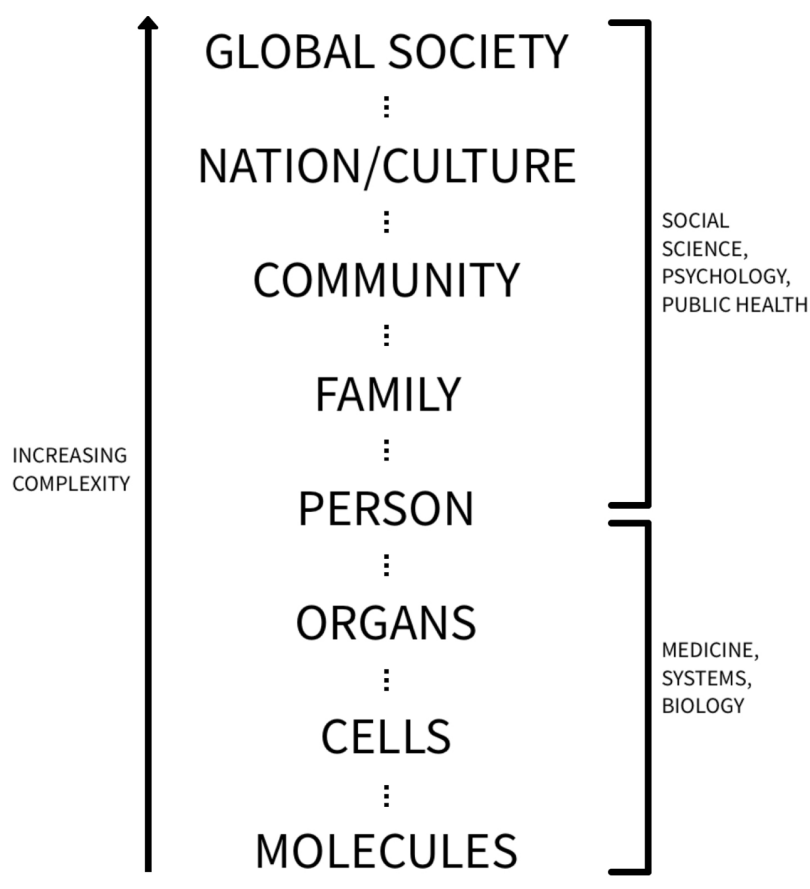

Figure 1 Hierarchically organised system of human health, adapted from Engel. ${ }^{28}$ proposed by Engel in the 1970 s. ${ }^{28}$ In the biopsychosocial model (figure 1), human health is presented as a hierarchically organised system of increasing complexity, going from molecular interactions at the subcellular level, to tissues, organs and eventually individual humans. Many of these interactions on the lower end of the hierarchy, such as gene expression and medication effects, are the domain of systems biology and much of the practice of clinical medicine. The biopsychosocial model continues vertically towards levels of greater complexity, including interactions of humans in family groups, communities and larger societies. These more macroscopic interactions, and strategies to address population health at the community, national and global levels, relate more to the fields of public health, psychology and the social sciences, including economics and political science.

Our vision of One Health expands on this single hierarchical system of human health, to include simultaneously the three interconnected systems of humans, animals and the environment (figure 2). Like the biopsychosocial model, each system is organised vertically in levels of increasing complexity, from very simple molecular components up to complex systems of the global biosphere and the global populations of humans and animals.

According to this framework, the One Health approach deals with the health-related interactions that occur between these systems at differing levels of complexity. Such interactions can take place at a molecular or cellular level: for example, the effect of environmental chemical exposures on cell receptors of humans or animals, or the exchange of antibiotic resistance genes between microbial communities of humans, animals or the environment. As with the biopsychosocial model for human health, many of these interactions can be described with systems biology or pathogen biology. Interactions can also occur at an individual level, such as the direct contact between a human and a companion animal in a household, and may require clinical interventions such as treatment of infection. At higher levels of interactions, such as community, national, regional and global population levels, other tools such as epidemiology, social and behavioural sciences, as well as atmospheric and geological sciences, and 'big data' expertise and approaches will be required.

In this way, the One Health approach can 'zoom out' to address macrolevel or 'planetary'-level interactions, such as the combined effect of growing human and animal populations on greenhouse gas emissions at the global/ biospheric scale.

\section{SCALING FROM PATHOGENS TO POPULATIONS}

One advantage of this expanded One Health framework is that it emphasises how interactions at clinical and local public health levels, such as emerging infectious diseases in individuals, households or communities, are connected to higher level, more complex threats to health and 


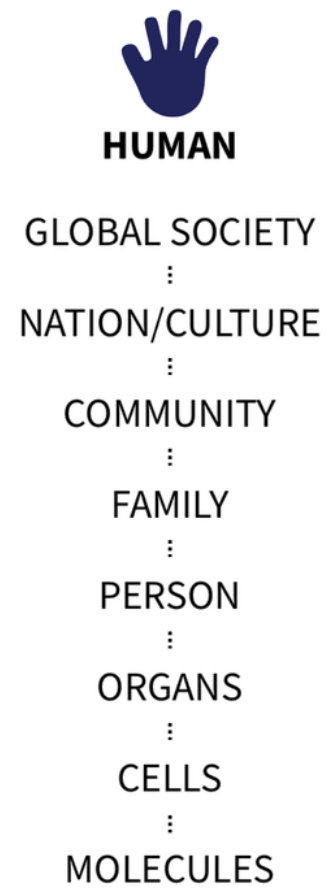

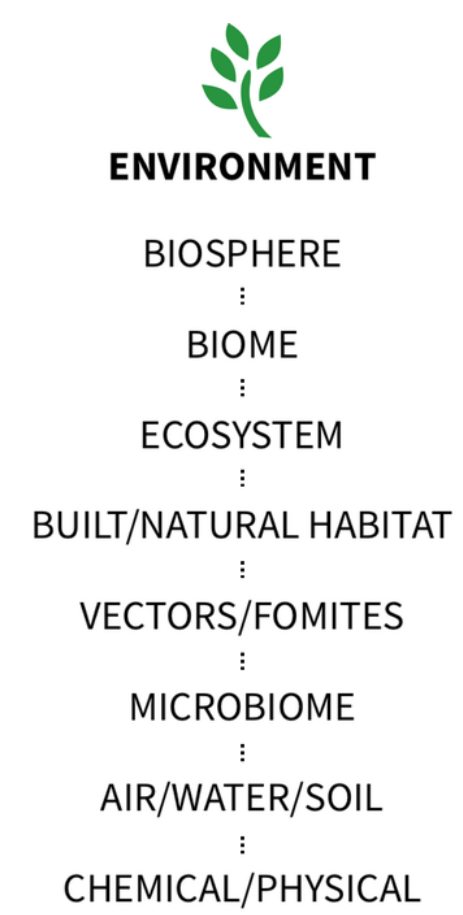

Figure 2 System levels for different types of One Health interactions.

sustainability, including factors such as climate change, deforestation, and how they are impacted through land and water use, types of food production, human behaviours, poverty, equity and governance.

As an example, characterisation of outbreaks of the zoonotic disease, Ebola, can be made at the individual level, where it is infecting humans, non-human primates and other animals. At this level, transmission events occur due to different types of contacts among and between humans and animals (eg, hunting, occupational, cultural practices, species-specific susceptibility and contaminated environmental sources). Addressing these problems involves knowledge of the viral transmission pathways and reducing contact between infected and susceptible individuals. At the more macroscopic level, however, the scope and severity of recent Ebola outbreaks may be related to deforestation, which is connected to local food insecurity and other uses of forests by expanding human and livestock populations, which are related in turn to cultural beliefs and practices, governance challenges and economic pressures. At a higher, national level, organisation of public health and economic systems affects education levels, access to healthcare and nutritious, affordable foods, and demographic trends including urbanisation and greater travel between villages and cities. These factors all have implications for agricultural systems and road building that affect the environment as well as both livestock and wildlife populations. Scaling up further involves consideration of regional changes in biodiversity and climate and the effect on bat reservoirs of the virus, and the effect of global travel patterns in moving the virus over large distances.

\section{ANIMALS AS SENTINELS}

In another scenario, a disease outbreak in an animal population, such as a sudden stranding of whales or other marine mammals, can capture the attention of the media and the public, raise questions on the causes of unexpected die-offs, and provide windows of opportunity for instituting needed, urgent solutions. While investigation of such events sometimes reveals a discrete proximate cause such as a viral infection or a toxic exposure, such a 'sentinel event' in animals may be an indicator of higher level environmental and human forces at play.

Figure 3 shows how an animal sentinel event at an individual or group level can be mapped to larger, often planetary-level forces, resulting in improved articulation of research questions and more effective solutions. For example, accumulation of plastics found in the stomach of a stranded marine mammal may be a sign of wider contamination of marine environments by microplastics related to changes in the use of plastics in the textile industry. ${ }^{29}$ Widespread pollution by microplastics has considerable economic ramifications, including concerns about unsustainable manufacturing processes that could be affecting aquatic ecosystems, including fisheries important to the human food supply. Addressing this problem, therefore, may require major changes on the part of manufacturers and consumers, involving national and international policy initiatives.

In another example, the outbreak of mercury poisoning among fish-eating residents of Minamata, Japan, due to contamination in local fish from the polluted bay ${ }^{30}$ was preceded by die-offs of fish and neurological disease events in cats and other animals. The event also showed 


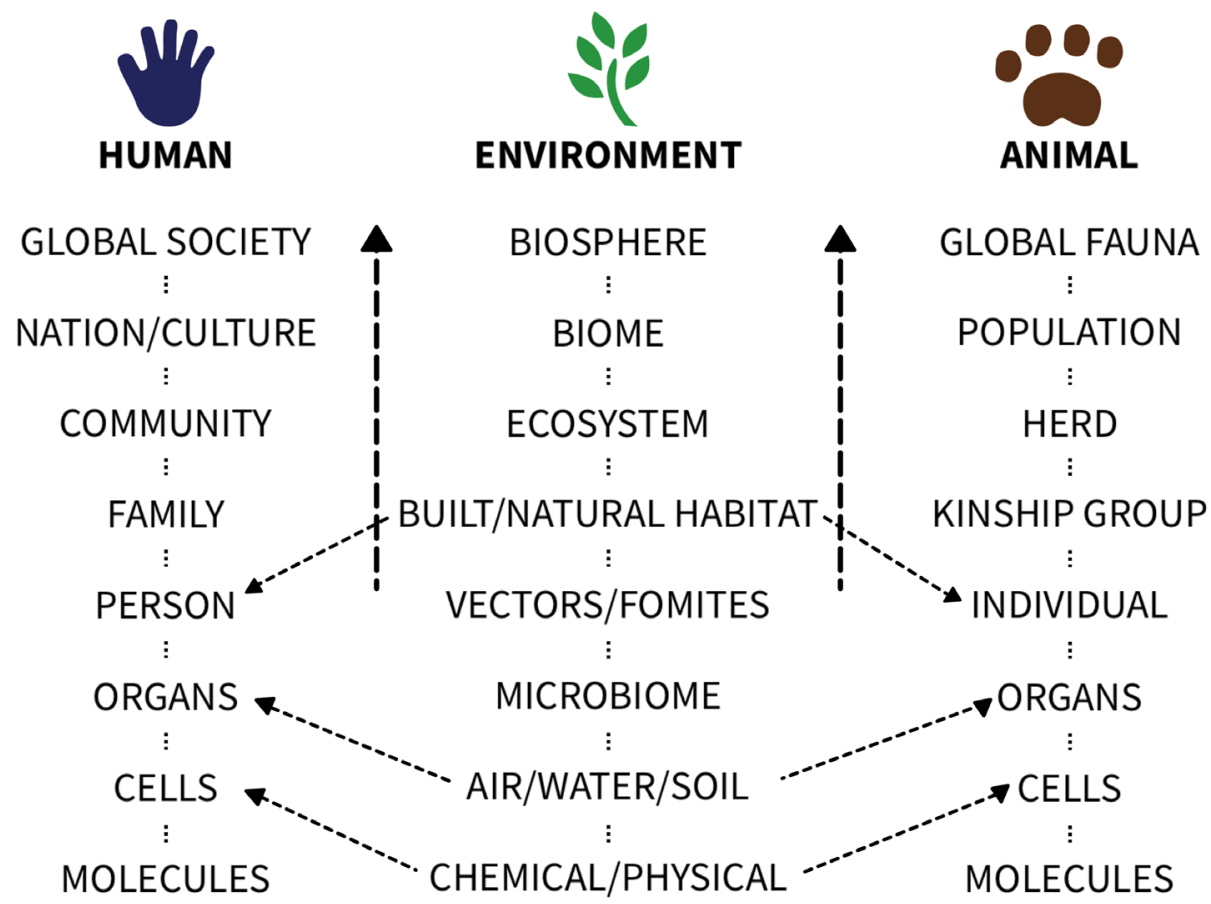

Figure 3 How sentinel events in animals and humans can provide warning of health threats at higher global and planetary levels.

the health danger of unregulated industrial manufacturing and widespread chemical pollution of the environment.

\section{SUSTAINABLE COEXISTENCE: HUMANS AND ANIMALS SHARING ENVIRONMENTS}

The One Health framework can be used not just to identify and control health threats, but also to identify positive models for healthy coexistence, well-being and sustainability of these interconnected systems. For example, a farm with animals, if managed using One Health principles that optimise the health and well-being of the humans (farm workers, farm families, community members and consumers) as well as the animals and the local environment (protecting forests and water supplies, reducing energy consumption, using renewable energy, and eliminating air and chemical pollution) can provide a model that, if replicated on a wider scale, could help mitigate the environmental consequences of agricultural food production. Assessing the sustainability of different types of farming practices in a One Health way requires skills of modelling and integration of human, animal and environmental outcomes on a larger scale, considering aspects such as carbon footprint and life-cycle assessment.

\section{WHY ANIMAL HEALTH MATTERS}

A recent European consensus statement described the key aspects of the One Health concept as interspecies equity (valuing animal health and well-being simultaneously with humans), stewardship and resilience. ${ }^{31}$ Yet why should the global health community concern itself with animal health issues? It could be argued that, given the urgency of environmental degradation described in the Planetary Health report, higher priority should go to actions that focus on the survival of humans. In this worldview, animals are viewed as part of the life-supporting environment, contributing to the rich and complex biodiversity of ecosystems (necessary for the survival, well-being and health of humans and other species) and providing nutrition for human populations (at the pinnacle of the food chain). Yet there are important reasons to apply instead a One Health framework that places intrinsic value on considering the health and well-being of animals separate from environmental considerations.

For one, the increasing number and rate of zoonotic disease events are directly related to the way that humans are managing land use, and wild and domestic animal populations, and therefore are likely to continue to occur. Simplistic solutions to zoonotic disease threats such as attempting to cull wildlife ${ }^{32}$ have proven futile in the past and are now understood to result in many negative unintended consequences for local people. Instead, we need to devise new and innovative methods of human coexistence with animals that will necessitate close cooperation between human, animal and environmental health professionals and other disciplines. Second, the relationship between animals and humans offers important economic and societal impacts, including many positive aspects in relation to non-communicable disease and health that are not adequately 
covered by a narrow focus on zoonotic disease. ${ }^{33} \mathrm{An}$ example is our growing understanding that contact with animals may have effects on the human microbiome that could have a beneficial impact on the risk of allergies and asthma. ${ }^{34}$

Third, as discussed above, animals can be the canary in the coal mine warning us of new threats from environmental change. Ignoring such disease events risks or placing a low priority to investigating and understanding them risks delays in our understanding of the health implications of a changing environment. Fourth, there is a growing ethical discussion about the intrinsic value of animal life as well as animal welfare that seems likely to continue, making it important to consider issues such as animal well-being when designing policies related to environmental sustainability or control of specific disease threats. ${ }^{35}$

Lastly, the human affection and attachment to animals that has evolved over thousands of years is also likely to continue, and can be a critical leverage point in finding ways to promote policy, family and individual actions to protect the ecosystems we depend on for life. For example, the Planetary Health report mentions the paradox of certain global burden of disease indicators currently improving despite the many warning signs of environmental degradation. By contrast, the increase in animal disease outbreaks and species extinctions, clearly with important environmental change drivers, may be easier for the public to connect with. This could help drive support for policy change.

\section{CONNECTING GLOBAL HEALTH TO SUSTAINABILITY}

This 'planetary' vision for One Health, therefore, encompasses important aspects of both the One Health and Planetary Health frameworks that facilitate going from 'local to global', or more accurately 'molecular to planetary', to address the health, well-being and sustainability of humans, animals and the environment. This allows for consideration of a wide range of local solutions to complex health challenges rather than a 'one size fits all' prescription that could result from a top-down approach. ${ }^{33}$ Employing a comprehensive One Health framework encourages multidisciplinarity in global health research, education, programme and policy assessments, planning, and implementation. It also requires further development of useful metrics for tracking One Health outcomes ${ }^{36}$ as well as better ways to assess impact. ${ }^{31}$

We encourage discussion and further development of this planetary One Health approach, and BMJ Global Health welcomes submissions based on the planetary One Health approach. Adopting the planetary vision for One Health will help to better connect ongoing global health efforts in disease control and preparedness to larger underlying and pressing issues of environmental change, equity and sustainability. Creating local models of healthy coexistence between humans and animal populations and the environments they share and depend on for life is critical for ensuring a sustainable future for our shared home of planet earth.

Acknowledgements The authors would like to thank Mr. Joshua Steele for graphic design.

Funding The authors have not declared a specific grant for this research from any funding agency in the public, commercial or not-for-profit sectors.

Competing interests None declared.

Patient consent Not required.

Provenance and peer review Not commissioned; internally peer reviewed.

Data sharing statement There are no additional data available.

Portions of this work were presented at the Fifth International One Health Congress, Saskatoon CA June 2018

Open access This is an open access article distributed in accordance with the Creative Commons Attribution Non Commercial (CC BY-NC 4.0) license, which permits others to distribute, remix, adapt, build upon this work non-commercially, and license their derivative works on different terms, provided the original work is properly cited, appropriate credit is given, any changes made indicated, and the use is non-commercial. See: http://creativecommons.org/licenses/by-nc/4.0/

\section{REFERENCES}

1. Whitmee $S$, Haines A, Beyrer C, et al. Safeguarding human health in the Anthropocene epoch: report of The Rockefeller Foundation-Lancet Commission on planetary health. Lancet 2015;386:1973-2028.

2. Wellcome Trust, 2018. Priority area: Our Planet, Our Healthresponding to a changing world. Available from: https://wellcome. ac.uk/what-we-do/our-work/our-planet-our-health [accessed $19 \mathrm{Jul}$ 2018].

3. Planetary Health Alliance, 2018. Available from: https://planetaryhea Ithalliance.org/home

4. The Lancet Planetary Health. Welcome to the lancet planetary Health. Lancet Planet Health 2017;1:e1.

5. Gibbs EP. The evolution of One Health: a decade of progress and challenges for the future. Vet Rec 2014;174:85-91.

6. Waltner-Toews D. Ecosystem sustainability and health. Cambridge University Press, 2004. ISBN: 0-521-53185-3.

7. Toppenberg-Pejcic D, Noyes J, Allen T. Emergency risk communication: lessons learned from a rapid review of recent gray literature on ebola, zika, and yellow fever. Health Commun 2018:1-19.

8. Robinson TP, Bu DP, Carrique-Mas J, et al. Antibiotic resistance is the quintessential One Health issue. Trans $R$ Soc Trop Med Hyg 2016;110:377-80.

9. Godlee F, Waters A. Healthy people, healthy animals, and a healthy environment: One Health. BMJ 2018;362:k3020.

10. FAO, OIE, WHO. The FAO-OIE-WHO Collaboration: sharing responsibilities and coordinating global activities to address health risks at the animal-human-ecosystems interfaces. A Tripartite Concept Note April 2010. Available from: http://www.who.int/ foodsafety/zoonoses/final_concept_note_Hanoi.pdf [Accessed 19 Jul 2018].

11. American Public Health Association, November 2017. Advancing a 'One Health' approach to promote health at the human-animalenvironment interface. Policy Number: 201712. Available from: https://www.apha.org/policies-and-advocacy/public-health-policystatements/policy-database/2018/01/18/advancing-a-one-healthapproach [accessed 19 Jul 2018].

12. $\mathrm{OH}$ EU, 2018. One health European Joint Programme. Available from: https://onehealthejp.eu/ [accessed 19 Jul].

13. The Fleming Fund, 2018. Available from: http://www.flemingfund. org/

14. CDCGlobal Health Security Agenda (GHSA), 2018. Implementing the Global Health Security Agenda: progress and impact from U.S. Government investments. Available from: https://www.ghsagenda. org/docs/default-source/default-document-library/global-healthsecurity-agenda-2017-progress-and-impact-from-u-s-investments. pdf [accessed 19 Jul 2018]

15. Global Risk Forum Davos, 2012. One Health - An integrative health risk management perspective. Available from: http://onehealth grforum.org/about/about-one-health/ [accessed 19 Jul 2018]. 
16. Prince Mahidol Award Conference 2018, 2018. Report of the 2018 conference on making the world safe from the threats of emerging infectious diseases. Available from: http://pmac2018.com/uploads/ downloads/PMAC2018 Proceeding E Version.pdf

17. USAID, 2016. One health workforce- developing a global workforce to prevent, detect, and respond to infectious disease threats. Available from: https://www.usaid.gov/sites/default/files/documents/ 1864/OHW_Overview_Handout_2016-ct-508-1.pdf

18. Khan MS, Rothman-Ostrow P, Spencer J, et al. The growth and strategic functioning of one health networks: a systematic analysis. Lancet Planet Health 2018;2:e264-273.

19. Degeling C, Johnson J, Kerridge I, et al. Implementing a one health approach to emerging infectious disease: reflections on the socio-political, ethical and legal dimensions. BMC Public Health 2015;15:1307.

20. Bardosh K. One health: science, politics and zoonotic disease in Africa. Routledge, 2016.

21. Manlove KR, Walker JG, Craft ME, et al. "One Health" or three? publication silos among the one health disciplines. PLoS Biol 2016;14:e1002448.

22. Schurer JM, Mosites E, Li C, et al. Community-based surveillance of zoonotic parasites in a 'One Health' world: a systematic review. One Health 2016;2:166-74.

23. Baum SE, Machalaba C, Daszak P, et al. Evaluating one health: Are we demonstrating effectiveness? One Health 2017;3:5-10.

24. Falzon LC, Lechner I, Chantziaras I, et al. Quantitative outcomes of a one health approach to study global health challenges. Ecohealth 2018;15:209-27.

25. Davis MF, Rankin SC, Schurer JM, et al. Checklist for One Health Epidemiological Reporting of Evidence (COHERE). One Health 2017;4:14-21.
26. Equator Network. Enhancing the quality and transparency of health research. Available from: http://www.equator-network.org/reportingguidelines/cohere/ [accessed 19 Jul 2018].

27. Lerner $\mathrm{H}$, Berg C. A comparison of three holistic approaches to health: one health, ecoHealth, and planetary health. Front Vet Sci 2017;4:163.

28. Engel GL. The biopsychosocial model and the education of health professionals. Ann N Y Acad Sci 1978;310:169-81.

29. Taylor ML, Gwinnett C, Robinson LF, et al. Plastic microfibre ingestion by deep-sea organisms. Sci Rep 2016;6:33997.

30. Rabinowitz P, Scotch M, Conti L. Human and animal sentinels for shared health risks. Vet Ital 2009;45:23-4.

31. Ruegg SR, McMahon BJ, Hasler B. A Blueprint to evaluate one health. Front public health. Front Public Health 2017;5.

32. Harrison A, Newey S, Gilbert L, et al. Culling wildlife hosts to control disease: mountain hares, red grouse and louping ill virus. J Appl Ecol 2010;47:926-30.

33. Hinchliffe S, . More than one world, more than one health: reconfiguring interspecies health. Soc Sci Med 2015;129:28-35

34. Tun HM, Konya T, Takaro TK, et al. Exposure to household furry pets influences the gut microbiota of infant at 3-4 months following various birth scenarios. Microbiome 2017;5:40.

35. Capps B, Bailey MM, Bickford D, et al. Introducing one health to the ethical debate about Zoonotic diseases in Southeast Asia. Bioethics 2015;29:588-96

36. Torgerson PR, Rüegg S, Devleesschauwer B, et al. zDALY: an adjusted indicator to estimate the burden of zoonotic diseases. One Health 2018;5:40-5 